\author{
Eric C. Hosten and Richard Betz*
}

\title{
The crystal structure of diaquahydrogen 2,5-dimethylbenzenesulphonate, $\mathrm{C}_{8} \mathrm{H}_{14} \mathrm{O}_{5} \mathrm{~S}$
}

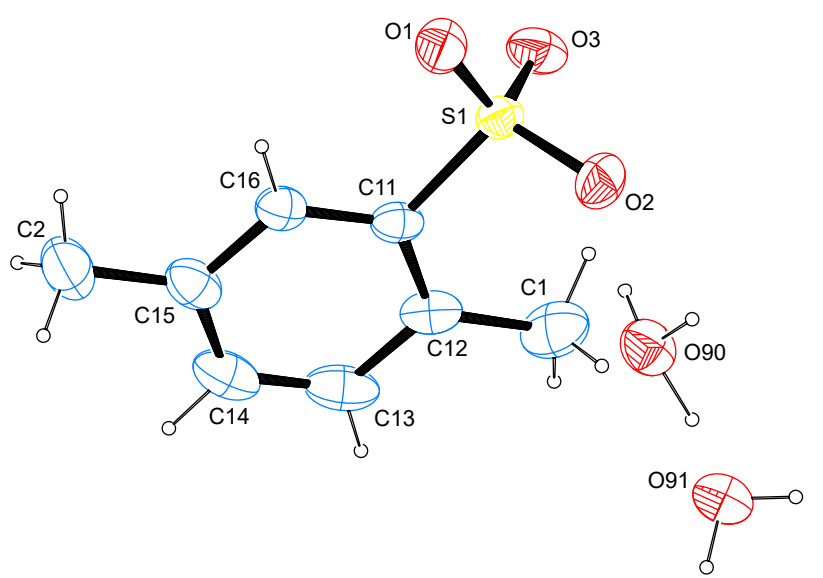

https://doi.org/10.1515/ncrs-2020-0595

Received November 12, 2020; accepted December 30, 2020;

published online February 12, 2021

\section{Abstract \\ $\mathrm{C}_{8} \mathrm{H}_{14} \mathrm{O}_{5} \mathrm{~S}$, monoclinic, $P 2_{1}$ (no. 4), $a=6.3783(4) \AA$, $b=8.2630(5) \AA, \quad c=10.5891(7) \AA, \quad \beta=90.877(2)^{\circ}$, $V=558.02(6) \AA^{3}, Z=2, R_{g t}(F)=0.0254, w R_{r e f}\left(F^{2}\right)=0.0715$, $\mathrm{T}=200 \mathrm{~K}$}

\section{CCDC no: 2053157}

The molecular structure is shown in the figure. Table 1 contains crystallographic data and Table 2 contains the list of the atoms including atomic coordinates and displacement parameters.

\section{Source of material}

The compound was obtained commercially (Merck). Crystals suitable for the diffraction study were taken directly from the provided product.

*Corresponding author: Richard Betz, Department of Chemistry, Nelson Mandela University, Summerstrand Campus (South), University Way, Summerstrand, PO Box 77000, Port Elizabeth, 6031, South Africa, E-mail: Richard.Betz@mandela.ac.za. https://orcid.org/ 0000-0002-5730-2152

Eric C. Hosten, Department of Chemistry, Nelson Mandela University, Summerstrand Campus (South), University Way, Summerstrand, PO Box 77000, Port Elizabeth, 6031, South Africa. https://orcid.org/ 0000-0003-4173-2550
Table 1: Data collection and handling.

\begin{tabular}{ll}
\hline Crystal: & Colourless platelet \\
Size: & $0.43 \times 0.24 \times 0.23 \mathrm{~mm}$ \\
Wavelength: & Mo $K \alpha$ radiation $(0.71073 \AA$ A $)$ \\
$\mu:$ & $0.29 \mathrm{~mm}^{-1}$ \\
Diffractometer, scan mode: & Bruker APEX-II, $\varphi$ and $\omega$ \\
$\theta_{\text {max }}$, completeness: & $28.4^{\circ},>99 \%$ \\
$N(h k l)_{\text {measured }}, N(h k l)_{\text {unique }}, R_{\text {int }}:$ & $5225,2626,0.012$ \\
Criterion for $I_{\text {obs }}, N(h k l)_{\mathrm{gt}}:$ & $I_{\text {obs }}>2 \sigma\left(I_{\text {obs }}\right), 2541$ \\
$N(\text { param })_{\text {refined }}:$ & 149 \\
Programs: & Bruker [1, 2], SHELX [3], \\
& WinGX/ORTEP [4], Mercury [5], \\
& PLATON [6] \\
\hline
\end{tabular}

Table 2: Fractional atomic coordinates and isotropic or equivalent isotropic displacement parameters $\left(\AA^{2}\right)$.

\begin{tabular}{lrrrr}
\hline Atom & $\boldsymbol{x}$ & $\boldsymbol{y}$ & $\boldsymbol{z}$ & $\boldsymbol{U}_{\text {iso }}{ }^{\star} \boldsymbol{U}_{\text {eq }}$ \\
\hline S1 & $0.25094(6)$ & $0.71542(5)$ & $0.81103(3)$ & $0.02902(12)$ \\
O1 & $0.0450(2)$ & $0.7896(2)$ & $0.82083(13)$ & $0.0409(4)$ \\
O2 & $0.2780(3)$ & $0.58300(19)$ & $0.90288(14)$ & $0.0410(3)$ \\
O3 & $0.4231(3)$ & $0.82997(19)$ & $0.82379(15)$ & $0.0411(4)$ \\
C1 & $0.6169(4)$ & $0.4929(3)$ & $0.7124(3)$ & $0.0509(6)$ \\
H1A & 0.657557 & 0.588421 & 0.761828 & $0.076^{*}$ \\
H1B & 0.736917 & 0.455540 & 0.663544 & $0.076^{*}$ \\
H1C & 0.572203 & 0.406614 & 0.769457 & $0.076^{*}$ \\
C2 & $-0.0600(4)$ & $0.6585(4)$ & $0.3547(2)$ & $0.0510(6)$ \\
H2A & 0.001984 & 0.707715 & 0.279841 & $0.076^{*}$ \\
H2B & -0.156354 & 0.735529 & 0.393599 & $0.076^{*}$ \\
H2C & -0.137050 & 0.560579 & 0.329998 & $0.076^{*}$ \\
C11 & $0.2663(3)$ & $0.6310(2)$ & $0.65808(16)$ & $0.0292(3)$ \\
C12 & $0.4395(3)$ & $0.5359(2)$ & $0.6240(2)$ & $0.0365(4)$ \\
C13 & $0.4386(4)$ & $0.4807(3)$ & $0.4992(2)$ & $0.0469(5)$ \\
H13 & 0.551135 & 0.414529 & 0.472265 & $0.056^{*}$ \\
C14 & $0.2806(4)$ & $0.5185(3)$ & $0.4134(2)$ & $0.0458(5)$ \\
H14 & 0.287529 & 0.478260 & 0.329580 & $0.055^{*}$ \\
C15 & $0.1109(3)$ & $0.6149(3)$ & $0.44792(18)$ & $0.0388(4)$ \\
C16 & $0.1058(3)$ & $0.6699(2)$ & $0.57263(17)$ & $0.0311(4)$ \\
H16 & -0.008450 & 0.734443 & 0.599455 & $0.037^{*}$ \\
O90 & $0.1295(3)$ & $0.2939(2)$ & $0.95464(15)$ & $0.0417(4)$ \\
H901 & $0.093(5)$ & $0.296(5)$ & $1.016(3)$ & $0.054(9)^{*}$ \\
H902 & $0.159(4)$ & $0.398(4)$ & $0.933(3)$ & $0.051(8)^{\star}$ \\
H903 & $0.277(6)$ & $0.206(5)$ & $0.946(3)$ & $0.072(9)^{\star}$ \\
091 & $0.4312(3)$ & $0.1268(2)$ & $0.91451(18)$ & $0.0516(4)$ \\
H911 & $0.488(7)$ & $0.107(6)$ & $0.984(4)$ & $0.088(13)^{*}$ \\
H912 & $0.401(5)$ & $0.024(5)$ & $0.880(3)$ & $0.070(10)^{\star}$ \\
\hline & & & &
\end{tabular}




\section{Experimental details}

Carbon-bound $\mathrm{H}$ atoms were placed in calculated positions (C-H $0.95 \AA$ A for aromatic carbon atoms) and were included in the refinement in the riding model approximation, with $U(\mathrm{H})$ set to $1.2 U_{e q}(\mathrm{C})$.

The $\mathrm{H}$ atoms of the methyl groups were allowed to rotate with a fixed angle around the $\mathrm{C}-\mathrm{C}$ bond to best fit the experimental electron density (HFIX 137 in the SHELX program suite [3]), with $U(\mathrm{H})$ set to $1.5 U_{e q}(\mathrm{C})$.

The $\mathrm{H}$ atoms of the water molecules as well as the bridging $\mathrm{H}$ atom of the $\mathrm{H}_{5} \mathrm{O}_{2}^{+}$cation were located on a difference Fourier map and refined freely. The position of the aforementioned bridging $\mathrm{H}$ atom was refined approximately midway between the two water $\mathrm{O}$ atoms, suggesting $\mathrm{H}$ atom disorder.

The Flack $x=0.070(16)$ parameter was determined using 1088 quotients [7].

\section{Comment}

Several simple and fundamental derivatives of benzene are powerful and versatile reagents in industry and academic research alike and have entered the preparative chemist's toolbox decades ago. One notable example for the latter statement are benzenesulphonic acid and its alkylated derivatives such as para-toluenesulphonic acid which are readily available upon reacting the parent hydrocarbon with concentrated sulphuric acid [8] and find widespread use as reagents of intermediate strength whose solubility in organic solvents is of crucial interest. In continuation of our interest in structural aspects of acidic derivatives of benzene [9-14] the molecular and crystal structure of the title compound was determined. Structural information about para-toluenesulphonic acid [15] as well as several compounds featuring the title compound bonding to main group elements such as tin $[16,17]$ is available in the literature.

The structure solution shows the presence of the 2,5-dimethylsulphonate scaffold as well as two molecules of water. A closer inspection of the hydrogen atom positions reveals the title compound to exist as a hydrated oxonium salt featuring the $\mathrm{H}_{5} \mathrm{O}_{2}^{+}$cation in the solid state. $\mathrm{S}-\mathrm{O}$ bond lengths measure 1.4545(15)-1.4724(15) $\AA$, which is in good agreement with values found for other deprotonated benzenesulphonic acid derivatives whose metrical parameters have been deposited with the Cambridge Structural Database [18].
The crystal structure is dominated by classical hydrogen bonds of the $\mathrm{O}-\mathrm{H} \cdots \mathrm{O}$ type involving all oxygen atoms of the sulphonate anion as acceptor. In terms of graph-set analysis [19, 20], the descriptor for these hydrogen bonds is $D D D D D$ at the unitary level. In total, the entities of the title compound are connected to double layers perpendicular to the crystallographic $c$ axis. $\pi$-Stacking does not play an important role in the crystal structure as the shortest distance between two centers of gravity was measured at 5.1042(13) Å.

Author contributions: All the authors have accepted responsibility for the entire content of this submitted manuscript and approved submission.

Research funding: National Research Foundation.

Conflict of interest statement: The authors declare no conflicts of interest regarding this article.

\section{References}

1. Bruker. APEX2; Bruker AXS Inc.: Madison, Wisconsin, USA, 2012.

2. Bruker. SADABS; Bruker AXS Inc.: Madison, Wisconsin, USA, 2008.

3. Sheldrick G. M. A short history of SHELX. Acta Crystallogr. 2008, A64, 112-122.

4. Farrugia L. J. WinGX and ORTEP for Windows: an update. J. Appl. Crystallogr. 2012, 45, 849-854.

5. Macrae C. F., Bruno I. J., Chisholm J. A., Edgington P. R., McCabe P., Pidcock E., Rodriguez-Monge L., Taylor R., van de Streek J., Wood P. A. Mercury CSD 2.0 - new features for the visualization and investigation of crystal structures. J. Appl. Crystallogr. 2008, 41, 466-470.

6. Spek A. L. Structure validation in chemical crystallography. Acta Crystallogr. 2009, D65, 148-155.

7. Parsons S., Flack H. D., Wagner T. Use of intensity quotients and differences in absolute structure refinement. Acta Crystallogr. 2013, B69, 249-259.

8. Becker H. G. O., Beckert R., Domschke G., Fanghänel E., Habicher W. D., Metz P., Pavel D., Schwetlick K. Organikum Organisch-chemisches Grundpraktikum, 21st ed.; Wiley-VCH: Weinheim, 2000.

9. Betz R., Gerber T. 2,4,6-Trifluorobenzoic acid. Acta Crystallogr 2011, E67, 0539.

10. Betz R., Gerber T. 2-(Trifluoromethyl)benzoic acid. Acta Crystallogr. 2011, E67, 0907.

11. Betz R., Gerber T., Schalekamp H. 2-Hydroxy-6-isopropyl3-methylbenzoic acid. Acta Crystallogr. 2011, E67, 01063.

12. Ndima L., Betz R. Redetermination of the crystal structure of 3-bromobenzoic acid, $\mathrm{C}_{7} \mathrm{H}_{5} \mathrm{BrO}_{2}$. Z. Kristallogr. NCS 2016, 231, 351-353.

13. Betz R., Gerber T. 2-Chloro-6-fluorobenzoic acid. Acta Crystallogr. 2011, E67, 01329.

14. Manana P., Hosten E. C., Betz R. The crystal structure of benzenesulphonic acid, $\mathrm{C}_{6} \mathrm{H}_{6} \mathrm{O}_{3}$ S. Z. Kristallogr. NCS 2021, 236. accepted. 
15. Arora S. K., Sundaralingam M. The crystal and molecular structure of 4-methyl sulfonic acid ( $p$-toluenesulfonic acid) monohydrate, $\mathrm{C}_{7} \mathrm{H}_{8} \mathrm{SO}_{3}^{-} \cdot \mathrm{H}_{3} \mathrm{O}^{+}$, an oxonium salt. Acta Crystallogr. 1971, B27, 1293-1298.

16. Chandrasekhar V., Singh P., Gopal K. Direct hydrolysis of hydrated organotin cations: synthesis and structural characterization of $\left\{\left[n-\mathrm{Bu}_{2} \mathrm{Sn}\left(\mathrm{OH}_{2}\right)(\mathrm{Phen})\left(\mathrm{O}_{3} \mathrm{SC}_{6} \mathrm{H}_{3}-2,5-\mathrm{Me}_{2}\right)\right]^{+}\right.$ $\left.\left[2,5-\mathrm{Me}_{2} \mathrm{C}_{6} \mathrm{H}_{3} \mathrm{SO}_{3}\right]^{-}\right\}$(Phen = 1,10-phenanthroline) and $\left\{\left[n-\mathrm{Bu}_{2} \mathrm{Sn}(\mu-\mathrm{OH})\left(\mathrm{O}_{3} \mathrm{SC}_{6} \mathrm{H}_{3}-2,5-\mathrm{Me}_{2}\right)\right]_{2}\right\}_{\mathrm{n}}$. Organometallics 2007 , 26, 2833-2839.

17. Kapoor R., Gupta A., Venugopalan P., Pannu A. P. S., Hundal M. S., Kapoor P. Structural studies of diorganotin(IV) sulfonates: the synthesis of $\left[\left(n-\mathrm{C}_{4} \mathrm{H}_{9}\right)_{2} \mathrm{Sn}\left\{\mathrm{OSO}_{2} \mathrm{C}_{6} \mathrm{H}_{3}\left(\mathrm{CH}_{3}\right)_{2}-2,5\right\}_{2}\right]$ and $\left[\left(n-\mathrm{C}_{4} \mathrm{H}_{9}\right)_{2} \mathrm{Sn}\left\{\mathrm{OSO}_{2} \mathrm{R}\right)_{2} \cdot 2\right.$ (hexamethylphosphoric triamide) $]$
$\left[\mathrm{R}=\mathrm{CH}_{3}, 4-\mathrm{C}_{6} \mathrm{H}_{4} \mathrm{CH}_{3}, 2,5-\mathrm{C}_{6} \mathrm{H}_{3}\left(\mathrm{CH}_{3}\right)_{2}, 2,4,6-\mathrm{C}_{6} \mathrm{H}_{2}\left(\mathrm{CH}_{3}\right)_{3}\right]$ and crystal structures of $\left[\left(n-\mathrm{C}_{4} \mathrm{H}_{9}\right)_{2} \mathrm{Sn}(\mu-\mathrm{OH})\left(\mathrm{OSO}_{2} \mathrm{C}_{6} \mathrm{H}_{3}\left(\mathrm{CH}_{3}\right)_{2}-2,5\right)\right]_{2}$ and $\left(n-\mathrm{C}_{4} \mathrm{H}_{9}\right)_{2} \mathrm{Sn}\left\{\mathrm{OSO}_{2} \mathrm{R}\right)_{2} \cdot 2$ (hexamethylphosphoric triamide)] $\left[\mathrm{R}=4-\mathrm{C}_{6} \mathrm{H}_{4} \mathrm{CH}_{3}, 2,5-\mathrm{C}_{6} \mathrm{H}_{3}\left(\mathrm{CH}_{3}\right)_{2}, 2,4,6-\mathrm{C}_{6} \mathrm{H}_{2}\left(\mathrm{CH}_{3}\right)_{3}\right]$. J. Organomet. Chem. 2009, 694, 623-629.

18. Allen F. H. The Cambridge Structural Database: a quarter of a million crystal structures and rising. Acta Crystallogr. 2002, B58, 380-388.

19. Bernstein J., Davis R. E., Shimoni L., Chang N.-L. Patterns in hydrogen bonding: functionality and graph set analysis in crystals. Angew. Chem. Int. Ed. Engl. 1995, 34, 1555-1573.

20. Etter M. C., MacDonald J. C., Bernstein J. Graph-set analysis of hydrogen-bond patterns in organic crystals. Acta Crystallogr. 1990, B46, 256-262. 